\title{
Investigación y formación docente en la educación superior. Tensiones y desafíos*
}

\author{
Carmen M. Belén Godino \\ Magíster en Sociedad e Instituciones \\ Universidad Nacional de San Luis, Argentina \\ belengodino@gmail.com
}

\author{
María Cecilia Montiel \\ Magíster en Dirección y Gestión de Centros Educativos \\ Universidad de Barcelona \\ Docente e investigadora de la \\ Universidad Nacional de San Luis, Argentina \\ mmontiel@gmail.com
}

\author{
María Luján Montiveros \\ Licenciada en Enseñanza Media y Superior, Ciencias de la Educación \\ Universidad Nacional de San Luis, Argentina \\ marialujanmontiverosgarro@gmail.com
}

\section{Cómo citar este artículo:}

Belén G., C. M., Montiel, M.C. y Luján M., M. (2015). Investigación y formación docente en la educación superior. Tensiones y desafíos. Espiral, Revista de Docencia e Investigación, 5(1), 9-36.

\section{Resumen}

Este artículo de reflexión presenta los resultados del Proyecto de Investigación Científico y Tecnológico (PICT2007-02029) en el que participaron tres universidades argentinas y tres instituciones de formación docente. En el artículo analizamos los resultados de la investigación pertenecientes a la sede de la Universidad Nacional de San Luis (Nodo 2, UNSL). El objetivo primordial fue desarrollar una mirada que analice transversalmente diversas perspectivas regionales sobre la formación docente en territorios marcados por la desigualdad social.

El equipo investigador adoptó la metodología de investigación colaborativa en red. Desde este enfoque, la red posibilita un intercambio dinámico entre personas, grupos e instituciones. Constituye un sistema abierto y en construcción que involucra a conjuntos que identifican necesidades y problemáticas comunes, y se organizan para potenciar sus recursos y favorecer la participación colaborativa.

En el artículo abordamos uno de los intereses investigativos del equipo de investigación: la problemática de la relación entre la investigación y la formación docente, en un escenario singular: el Instituto de Formación Docente San Luis.

Si bien en las últimas décadas se observa una clara intencionalidad política de instalar la práctica investigativa en los institutos de formación docente, esto ha presentado configuraciones singulares en la Institución analizada.
Podemos decir que si bien existen ciertas condiciones institucionales novedosas, que favorecen las actividades de investigación, la relación investigación-docencia es percibida por los actores institucionales como una relación en tensión. Esta tensión remite en definitiva a las significaciones atribuidas a la docencia y a su relación con la construcción del conocimiento.

Palabras clave: Formación docente, investigación, políticas educativas, institutos de formación, universidades nacionales.

\begin{abstract}
This reflection paper presents the results of the Scientific and Technological Research Project (PICT -200702029) in which three Argentine universities and three teacher training institutions participated. In the paper we analyze the research findings belonging to the $\mathrm{Na}$ tional University of San Luis. (Node 2 UNSL) The main objective was to develop an outlook that analyzes different regional perspectives on teacher training in areas marked by social inequality.

The research team adopted the methodology of collaborative research network. From this approach, the network enables a dynamic exchange between individuals, groups and institutions. It is an open system, which is in construction, and involves sets that identify common needs and problems, and are organized to strengthen their
\end{abstract}

* Artículo de reflexión adscrito al Proyecto de Investigación Científico y Tecnológico (PICT-2007-02029) en el que participaron tres universidades argentinas y tres instituciones de formación docente. 
resources and encourage collaborative participation.

This paper is addressed to one of the research interests of the research team: the problem of the relationship between research and teacher training in a unique setting: the Institute of Teacher Education San Luis.

Although in recent decades a clear political intention to install research practice in teacher training institutes is observed, this has presented unique settings in the institution analyzed. We can say that although there are certain novel institutional conditions that favor the research, research-teaching relationship is perceived by institutional actors as a tense relationship. This tension points definitively to the meanings attributed to teaching and its relationship to the construction of knowledge.

Keywords: Teacher training, research, educational policies, training institutes, national universities.

\section{Introducción}

El artículo que aquí se presenta es fruto del proceso de investigación llevado a cabo en el marco del Proyecto Científico y Tecnológico (PICT-2007-02029): Formación docente sobre comunicación, instituciones y ciudadanía en territorios marcados por la desigualdad social, desarrollado durante los años 2010-2012. Participaron de este proyecto tres universidades nacionales: Universidad de Buenos Aires (UBA), Universidad Nacional de San Luis (UNSL) y Universidad Nacional del Centro de la Provincia de Buenos Aires (UNCPBA), y tres instituciones de formación docente de las ciudades de Buenos Aires, Tandil y San Luis, las que se organizaron en tres nodos de trabajo.

Cada uno centró su atención en el estudio de un ámbito del campo de la formación docente, a saber: Comunicación y lenguajes (UBA-ISFD); Gestión y dinámicas institucionales (UNSL-IFDC); Educación, ciudadanía y democracia (UNICEN-ISFD). De esta manera se buscó promover y desarrollar una práctica de investigación colaborativa entre docentes de universidades nacionales y docentes de institutos de formación docente.

La experiencia se basó en la constitución de redes mediante un accionar en nodos interco- nectados, que a su vez actuaron como centros independientes, con autonomía relativa y un accionar articulado por objetivos y propósitos comunes. El trabajo se orientó a la creación de una estructura de intercambio e interacción entre grupos autónomos, que funcionaban de modo descentralizado respecto de las decisiones, planificación y evaluación de actividades, objetivos y metas respectivas.

Cada Nodo profundizó específicamente en uno de los ejes centrales del proyecto, suponiendo que el tratamiento conjunto de problemáticas de carácter institucional, comunicacional y ético-políticas redundaría en la generación de nuevos conocimientos más complejos y más ajustados a la realidad de la formación docente en territorios de desigualdad social.

En lo que respecta concretamente al Nodo 2 , centrado en la temática referida a la "Gestión y las dinámicas institucionales en la formación docente", y del cual formamos parte, se planteó entre sus objetivos indagar la práctica investigativa en los institutos de formación docente de San Luis (IFD), a través de explorar las temáticas en las que se investiga, el grado de participación de los docentes y alumnos en la constitución de equipos de investigación y los factores que facilitan u obstaculizan el proceso de investigación.

Indagar la práctica investigativa en los IFD, supone poner en discusión el tema del docente como investigador en el espacio de la formación docente. Este ha tenido un gran impulso en las últimas décadas en el ámbito académico y ha logrado instalarse con más fuerza en el discurso pedagógico, a partir de la implementación de las políticas educativas nacionales de Argentina. Muchos autores plantean la necesidad de cambiar una cultura institucional (Sarlé, 2007); renovar las instituciones formadoras (Vaillant, 2007); integrar las prácticas de formación inicial e investigativas (Noriega y Godino, 2011). Por otro lado, tam- 


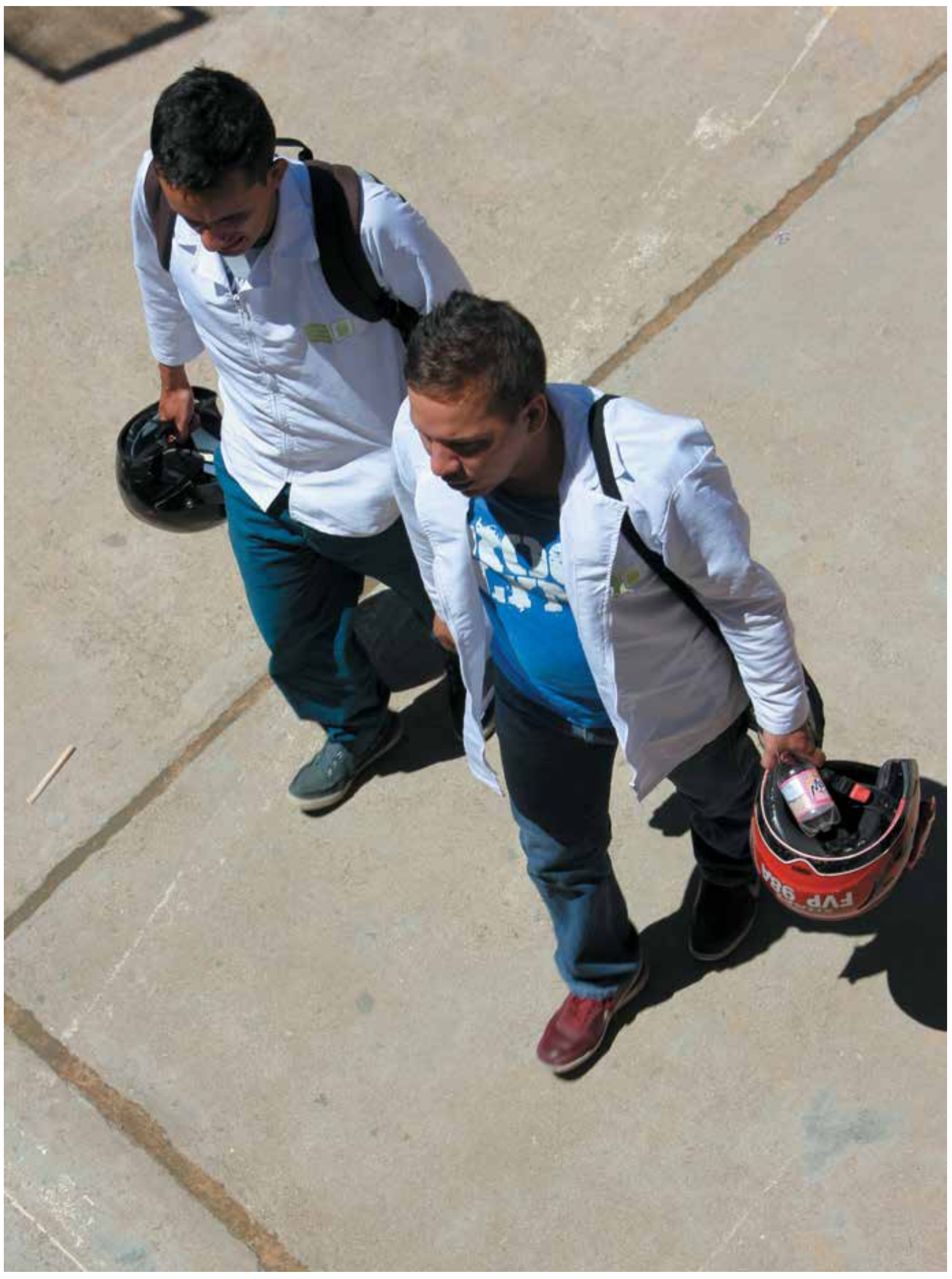


bién se ha profundizado en las discusiones sobre la figura del docente-investigador (Enriquez, 2012) como actor clave en el proceso de transformación de las instituciones.

La investigación, reservada solo para las instituciones universitarias, y casi vedada en el nivel terciario, se sitúa en estos últimos años como uno de los grandes desafíos por desarrollar en las instituciones de formación docente. Así y todo, en los IFD -y a diferencia de las universidades- el enfoque de la investigación se encuentra todavía bastante acotado: se orienta específicamente a la producción de saberes que colaboren a comprender y mejorar las prácticas de formación docente. La investigación educativa, entonces, se establece como:

Una de las funciones del nivel de Educación Superior (no universitario) que ha ido constituyéndose en un espacio valioso para responder al propósito de producir saberes pedagógicos. La especificidad de estos saberes sobre la enseñanza, la formación y el trabajo docente permiten visibilizar y comprender los desafíos y las complejidades que atañen a las tareas de esta profesión (Documento INFOD, 2013, p.3).

Rama (2006) analiza las características de lo que denomina Segunda Reforma de la Educación Superior en Latinoamérica, haciendo referencia al proceso de reestructuración y redefinición de las instituciones de educación superior, que se generó en la región a partir de los años ochenta, producto de la mercantilización, la expansión de la educación privada y la diferenciación del sistema superior.

Entre los cambios ocurridos en la formación docente, señala como uno de los más significativos, el carácter universitario atribuido a las instituciones formadoras. Esta transformación se ha dado de muchas maneras: a través de la transformación de las instituciones terciarias (escuelas normales) en institutos universitarios; por medio de su absorción a universidades; o a partir de la creación de nuevas instituciones formadoras de docentes, con los nuevos perfiles requeridos por la reforma, tal como es el caso del Instituto de Formación Docente San Luis.

Sin duda, la incorporación de la investigación en las carreras de formación docente y las reformas de sus instituciones, tiene por objeto intentar aproximarlas a la lógica de los sistemas universitarios, proceso que se ha desarrollado presentando profundas contradicciones. Entre ellas se destaca la tensión entre esta nueva función y los mandatos fundacionales de las instituciones de formación docente, más cercanos a la enseñanza que a la producción de conocimiento. Así también, la tensión entre las exigencias derivadas de estas nuevas funciones y los perfiles profesionales y de formación de los docentes de los IFD y finalmente, pero sin agotar la complejidad de la situación, el nuevo mandato de desarrollar las actividades de investigación.

Los nuevos escenarios y demandas planteadas a las instituciones formadoras de docentes, interpelan concepciones y dispositivos de formación, por lo que requieren ser estudiados en los espacios singulares de las organizaciones. Llevados por esta inquietud e interés por la temática, pero también desde la responsabilidad que nos atraviesa como docentes investigadoras, presentamos algunos de los resultados más significativos obtenidos.

En primera instancia, abordamos la problemática de la relación entre la investigación y la formación docente, a partir del recorrido que el grupo del proyecto de investigación ha venido realizando durante los últimos años. Para ello, se presenta el marco conceptual que guió el análisis sobre la relación entre la formación, la práctica docente y la investigación. Posteriormente, realizamos un breve recorrido por los principales lineamientos de la política educativa nacional orientados a fijar una determinada relación entre la formación y la investigación. Luego, nos aproximamos al plano 
institucional (instituto de formación docente - universidad) describiendo cómo las políticas han sido traducidas e interpretadas en el marco de la singularidad de su espacio institucional.

Finalmente, describimos el taller realizado en el marco de las primeras Jornadas de Formación Docente del Proyecto en Red, en donde recuperamos las voces de los actores participantes. Nos interesa focalizar aquí sus maneras de entender la tensión entre la formación docente y la investigación.

A partir de dicha experiencia y del recorrido analítico seguido en el trabajo, arribamos a las conclusiones que lejos de ser determinantes y cerradas, dejan abiertos nuevos interrogantes para seguir pensando e investigando.

\section{El proceso de investigación: características generales de su desarrollo}

El objetivo general de la investigación se definió de la siguiente manera:

Explorar estrategias de colaboración entre Universidades en Red e Institutos de Formación Docente, para avanzar en el conocimiento de los procesos habituales de formación docente sobre investigación y sobre contenidos de comunicación, institución escolar y ciudadanía, en contextos de desigualdad social y pobreza urbana; e indagar alternativas posibles dirigidas a disminuir la segmentación/fragmentación del sistema educativo (Documento Proyecto de Investigación Científica y Tecnológica, 2007 - Temas Abiertos - Red).

Este abordaje tuvo como finalidad:

- Desarrollar procesos de investigación participativa experiencial y construcción de conocimientos entre docentes superiores y universitarios con carácter formativo en ambas direcciones.

- Explorar los obstáculos y las posibilidades de colaboración entre las universidades y los IFD y entre sus docentes.
- Elaborar propuestas innovadoras, sustentadas en lo empírico, el análisis, y la elaboración teórica.

- Constituir espacios de construcción de conocimiento para docentes y alumnos de ambas instituciones, proceso en el cual la misma relación entre universidades, docentes en ejercicio e IFD será objeto de indagación.

En los tres nodos, la carrera de formación docente que se analizó fue el profesorado de educación primaria. Desde el nodo 2 nos interesaba analizar en el interior de cada institución las formas, experiencias y relatos, tanto en relación con los aspectos generales estructurantes del campo de la formación docente, como aquellos particulares de cada institución relativos a la preparación de futuros formadores, como a sus requerimientos.

Nuestro trabajo se propuso una estrategia mixta, con un abordaje fundamentalmente cualitativo y un diseño flexible. El diseño fue diacrónico, longitudinal. Como diseño longitudinal procuró la recolección y el análisis de datos referidos a aspectos similares a lo largo de los tres años. A su vez, participativo, porque docentes, alumnos de IFD y docentes universitarios fueron simultáneamente objetos y sujetos activos de la investigación, interactuantes, retro alimentadores del proceso y de la construcción teórica.

La lógica de la investigación participativa permite desarrollar actividades de investigación y de formación desde una perspectiva que involucra el respeto de las culturas institucionales. Sabemos que los mandatos históricos, las dinámicas institucionales y las finalidades que persiguen tanto las universidades como los IFD son diferentes, por tal motivo, fue sumamente necesario conocer en profundidad los aspectos nodales que caracterizaban sus culturas, para generar la participación activa de los sujetos desde posiciones colaborativas. 
Planteamos la investigación colaborativa como opción metodológica, retomando parte de los aportes teóricos y prácticos que nos proporcionan Rigal y Sirvent (2011) al referirse a la investigación acción participativa (IAP), sabiendo que nuestro proceso no adoptó esa perspectiva en su totalidad, pero sí nos posibilitó pensarnos como actores que integraban una red colaborativa. Para los autores citados la IAP:

Es un modo de hacer ciencia de lo social que procura la participación real de la población involucrada en el proceso de objetivación de la realidad en estudio, con el triple objetivo de generar conocimiento colectivo crítico sobre dicha realidad, fortalecer la organización social y la capacidad de participación de los sectores populares y promover la modificación de las condiciones que afectan su vida cotidiana (Rigal y Sirvent, 2011, p. 6).

El grupo pudo ampliar la mirada del trabajo en red sabiendo que la cultura colaborativa que este tipo de trabajo posibilita, pretende diluir las representaciones en relación con las diferencias de "jerarquías" entre las instituciones formadoras de docentes y las universidades, y empoderar a los docentes investigadores de ambas instituciones para pensar los requerimientos para el cambio (Corti, 2013).

Las técnicas utilizadas fueron fundamentalmente cualitativas: entrevistas, observaciones, grupos de reflexión, análisis de documentos. La información se recolectó a partir de distintos soportes: apuntes, fotografías, grabaciones, filmaciones, que permitieron después tratarlas como textos, analizar la información reunida y construir los datos. También se trabajó con encuestas destinadas a estudiantes y docentes para indagar diversos aspectos institucionales.

Al inicio y al final del estudio fue posible realizar una mirada transversal comparativa entre jurisdicciones. En consecuencia, la diversidad geográfica permitió la triangulación entre jurisdicciones. La diversidad de miradas permitió también la triangulación entre investigadores: docentes de IFD, docentes universitarios y estudiantes de IFD.

A continuación mencionamos algunas de las tareas realizadas específicamente en el nodo 2 que nos permitieron pensar nuestra investigación en red:

- Indagación mediante cuestionarios cerrados (2010 - 2011) a estudiantes y docentes de la carrera de Profesorado en Educación Primaria sobre las expectativas en relación con la carrera; motivos de elección de la carrera; percepción de la formación; evaluación sobre los aspectos administrativos-organizacionales; espacios que frecuenta en la institución, entre otros.

- Formación de grupos de reflexión y análisis de fuentes secundarias, sobre las preocupaciones, intereses de estudio del grupo de investigadores.

- Conocimiento (en los espacios institucionales de trabajo) de las condiciones laborales, expectativas, problemáticas de los docentes participantes del proyecto y de las características de los estudiantes de primero y segundo año del Profesorado, considerando así el contexto donde desarrollan su tarea desde una perspectiva de totalidad e integralidad.

- Encuentros periódicos del grupo de investigación para indagar las representaciones facilitadoras e inhibidoras del trabajo en conjunto y hacer consciente el atravesamiento de múltiples implicaciones, garantizar la horizontalidad de las relaciones y participación de todos los integrantes del grupo, evitando la monopolización de la palabra, el privilegio de ciertas opiniones por sobre otras y la centralidad del poder en unos pocos.

- Elaboración de registros exhaustivos de cada uno de los encuentros del grupo, 


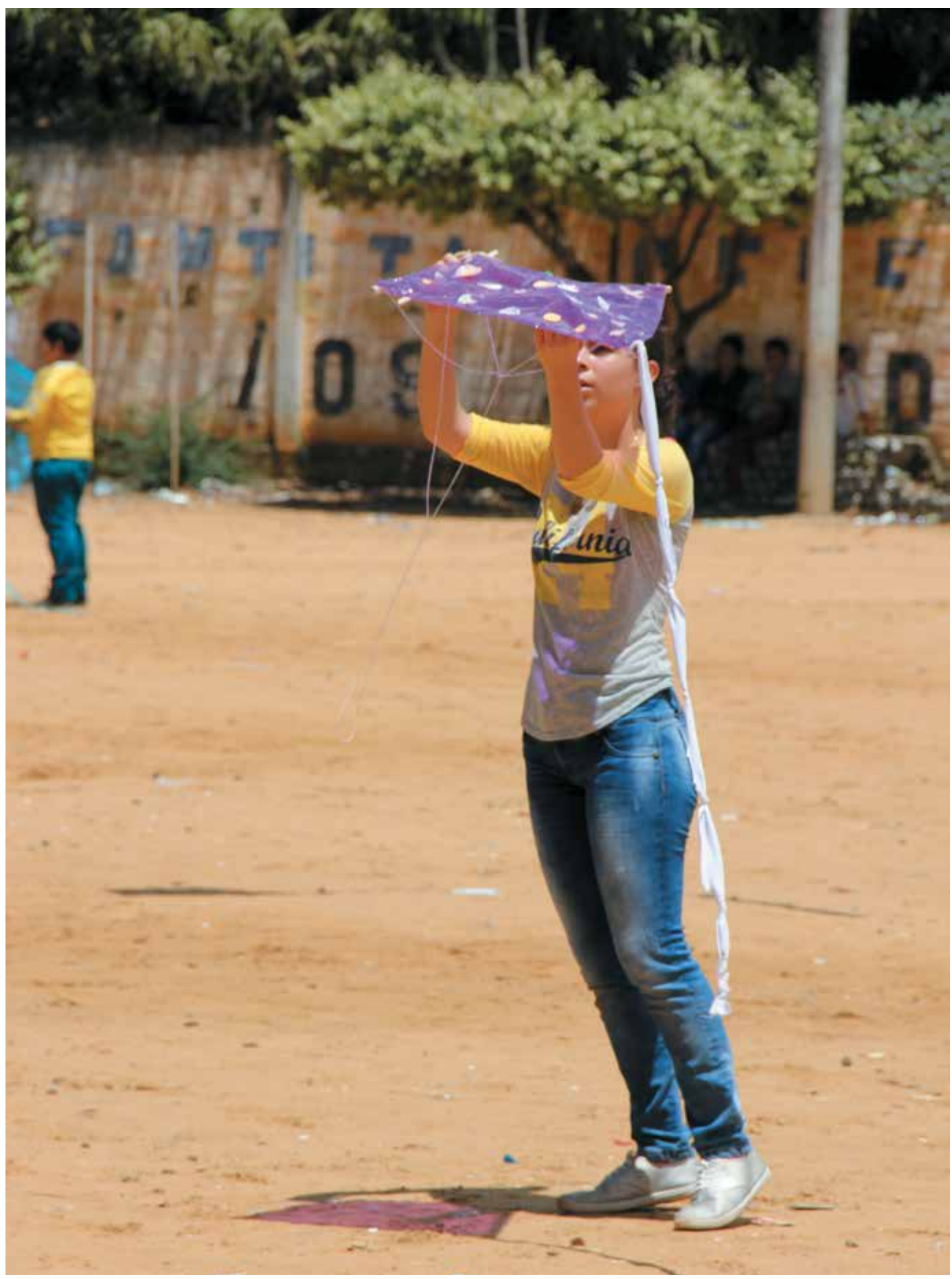


intentando entre todos registrar la circulación del poder.

- Análisis detallado y profundo de los registros narrativos de las reuniones de trabajo y del consenso intersubjetivo, interpretación y sentidos compartidos, a través del intercambio y revisión conjunta de los informes y de las producciones teóricas desarrolladas.

En relación con el proceso metodológico detallado se confeccionaron los primeros documentos de análisis de la información recolectada (período 2010 - 2011). Con base en las primeras aproximaciones de nuestro objeto de estudio, se pensó en la realización de un primer encuentro con el fin de socializar los avances de la investigación. También, como escenario de intercambios, para que los actores involucrados en la formación pudieran comunicar los resultados de investigaciones realizadas, presentar análisis de experiencias educativas y expresar opiniones en relación con el quehacer docente actual.

\section{El docente-investigador. Aproximaciones conceptuales iniciales}

\section{La investigación y los modelos teóricos de formación docente en Argentina}

Sin lugar a dudas, es posible advertir en los últimos años, cierta ruptura e interpelación de concepciones y políticas referidas a la formación, a los sujetos y a las instituciones formadoras que fueron hegemónicas por mucho tiempo en el campo de la formación docente. Sin embargo, no es posible obviar su permanencia, pues fueron las matrices de origen a partir de las cuales se constituyeron como tal los dispositivos de formación.

La conformación de un modelo de formación es fruto del interjuego de fuerzas instituidas e instituyentes que, inscritas en un contexto histórico, luchan por imponerse, delimitan- do formas de actuar, pensar y sentir. Modelos que, lejos de ser lineales, cerrados y puros, se interrelacionan e integran a lo largo del tiempo tomando nuevas formas y significados, operando como orientadores de la acción.

Davini (1995) señala cuatro modelos o tradiciones hegemónicas en la formación docente:

El modelo o tradición normalizadora-disciplinadora, cuya base filosófica política -sostenida por un Estado oligárquico-liberal- estaba constituida por discursos que propendían a la construcción de la hegemonía de la sociedad civil, a disciplinar a las grandes masas y formar un sujeto político-social, "el ciudadano". Para ello se conformó el Sistema Educativo Argentino, a partir del cual, la escuela y el docente se constituyen en protagonistas fundamentales para la socialización-disciplinamiento de la población requerida por el proyecto de las elites agrarias y urbanas. La institucionalización del rol docente se constituye en un aspecto fundamental para la transmisión de los patrones de comportamiento, pensamiento y valoración, estructurante del "proyecto civilizador". De esta manera, se posiciona a los docentes y las escuelas en un lugar pasivo, de receptor, en tanto tienen escaso margen para reinterpretar y desarrollar ese texto político que llegaba a las instituciones (Miranda, 2011).Para Southwell (2011):"(..) el normalismo constituye uno de los discursos pedagógicos más influyentes dentro del espacio educativo y cultural (...) convirtiéndose en una matriz de pensamiento para muchas generaciones de educadores" (p. 171).

Su actualidad en las prácticas de formación docente es señalada por Romano (2011), situación que choca, según el autor, con la retórica de lo dinámico, lo mutable y lo diferente de los discursos oficiales y de la pedagogía de moda/ dominante.

El modelo o tradición académica, que ha tenido y aún tiene mayor peso en los niveles medio y superior que en la enseñanza básica. Lo 
principal para esta tradición en la formación y acción de los docentes es el dominio de la disciplina que se enseña, debilitando la formación pedagógica considerada como innecesaria y hasta un obstáculo para la formación docente. Conocer sólidamente la asignatura, otorgando así gran importancia a los contenidos, hacía que se silenciaran otros debates pedagógicos que configuran también la práctica docente.

La tercera es la denominada tradición eficientista que, situada en la década del sesenta, mira al oficio docente desde la productividad de su labor, implementando minuciosos controles técnicos. Planificadores, evaluadores y supervisores entran en escena al desarrollar tareas especializadas y específicas en la educación, donde el docente debía constituirse en un técnico especializado que planifica y controla los tiempos y espacios de su tarea. La racionalidad tecnocrática reduce la formación docente a elementos meramente instrumentales y de productividad, dado que la educación debe contribuir a la formación de individuos para los nuevos puestos de trabajo en el ámbito productivo.

Y por último, el modelo hermenéutico-reflexivo supone a la enseñanza como una actividad compleja, en un ecosistema inestable, sobre determinada por el contexto espacio temporal y sociopolítico y cargada de conflictos de valor que requieren opciones éticas y políticas (Pérez Gómez, 1996). El docente debe enfrentar, con sabiduría y creatividad, situaciones prácticas imprevisibles que exigen a menudo resoluciones inmediatas para las que no sirven reglas técnicas ni recetas de la cultura escolar.

Otros autores retoman los aportes de este paradigma y lo denominan "crítico situacional" en el cual la enseñanza se comprende como un escenario complejo donde el docente conocedor de los contenidos disciplinares logra leer la realidad en la cual le toca trabajar, para después diseñar propuestas metodológicas adecuadas al particular entorno sociocultural (Giroux, 1984; Apple, 1989). “Desde esta perspectiva habría un entrecruzamiento de tres lógicas: disciplinar, lo metodológico situado y la realidad" (citado en Dabin y Calafato, 2005, p. 3).

La formación, expresa Ferry (2008), es una dinámica de desarrollo personal que consiste en tener aprendizajes, hacer descubrimientos, encontrar gente, desarrollar a la vez sus capacidades de razonamiento y también la riqueza de las imágenes que uno tiene del mundo. Es también poder descubrir sus propias capacidades, sus recursos y no es para nada evidente que esta dinámica, estos descubrimientos, estas transformaciones, sean producidos solo y principalmente por las instituciones educativas o por los aprendizajes formales que desde estas se propician.

La formación supone entonces procurar encontrar la articulación entre el recorrido personal y las exigencias institucionales de la formación profesional. De alguna manera, este posicionamiento implica considerar y favorecer el desarrollo de la persona, docente formado o en formación, desde su complejidad, como sujeto político, capaz de actuar desde un pensamiento autónomo, individual y colectivamente en el seno de las instituciones, potenciado su crecimiento personal y profesional y así poder educar a "otros" desde una perspectiva ética y política que les permita tener poder sobre sus actos, sentirse protagonistas del cambio institucional y social.

Es relevante también retomar la mirada que realiza Sánchez Gamboa (2010) en relación con lo que él denomina pedagogía de la respuesta, por encima de la pedagogía de la pregunta. Categorías interesantes para analizar y comprender el lugar de la investigación -pedagogía de la pregunta ${ }^{1}$ - en la formación y en la práctica profesional de docentes de escuelas primarias y medias.

1 Planteado así a partir de lo que el epistemólogo Bachelard enuncia "para el conocimiento científico cualquier conocimiento es una respuesta a una pregunta si no hay pregunta no puede haber conocimiento científico. Nada se da; todo se construye" (2010, p.189). 
El citado autor parte de considerar al "conocimiento" y al "saber acumulado" como conceptos cuyos procesos de construcción y finalidad son diferentes, pero a la vez establecen una relación dialéctica al momento de construir la pregunta y buscar la respuesta:

(...) se colocan en forma opuesta y contradictoria, en el mismo proceso. En cuanto el conocimiento se refiere a la parte dinámica en el proceso de construir preguntas y producir respuestas nuevas, los saberes se refieren al producto, a las respuestas elaboradas, fechada, sistematizada para ser distribuida, divulgada y consumida $(2009$, p. 7).

Los modelos de formación se inscriben en el marco de políticas que, enmarcadas en un contexto histórico, social particular no propiciaron el desarrollo de propuestas de formación en donde sea posible la articulación entre la pedagogía de la pregunta y la pedagogía de la respuesta y, por lo mismo, de valorizar procesos tendiente al desarrollo de una actitud investigativa, posibilitadora de la pregunta y de la respuesta en contextos educativos signados por la complejidad.

Una vez planteado lo que entendemos por formación y las tensiones que en esta se presentan respecto de la investigación, podemos interrogarnos: ¿A qué tipo de procesos de construcción de conocimientos nos referimos cuando hablamos de investigación en la práctica (u oficio) docente?

\section{El docente-investigador una forma de} vincular la investigación educativa y la práctica docente

La noción de docente-investigador expresa en el fondo, una idea relativamente simple que siempre ha estado en la tradición de los educadores comprometidos, y que alude al hecho de que los seres humanos son sujetos capaces de construir un pensamiento independiente, una conciencia crítica, y por lo tanto, pueden actuar libremente conforme a ello. Esta idea se funda en el derecho inalienable que tienen todos los seres humanos de crear y recrear saberes que les permitan comprender o transformar su realidad. En este sentido, emplear la investigación no solo es una necesidad teórica sino una exigencia de la práctica.

Stenhouse (1991) y Hopkins (1989), en Inglaterra, fueron los impulsores de la figura del docente-investigador, fijando la necesidad de convertirse en sujetos de reflexión y acción de su propia práctica de enseñanza. Para ellos, la autonomía es el núcleo central e impulsor del proceso investigativo. Asimismo, estos autores no descuidan que la función principal del profesor es la de enseñar y ningún método de investigación debe interferir en dicha tarea. Los autores reconocen que:

Los docentes-investigadores son los sujetos que están en mejores condiciones para captar las visiones y preocupaciones de los diversos actores educativos, porque ellos conocen el lugar, ubican las coordenadas que permiten precisar los problemas, saben la historia de la escuela y reconocen el sentido que los sujetos atribuyen a sus contextos particulares (Enriquez, 2012, p. 41).

Las posiciones mencionadas impulsan la investigación como una actividad docente individual y autónoma. Existen en la literatura educativa otras visiones sobre la figura del docente investigador, por ejemplo, Ward y Tikunoff (1982), Pine (1981) y Bartolomé y Anguera (1990), Rigal y Sirvent (2011), Enriquez, P. (2012), entre otros, han difundido un modelo de investigación fundado en la cooperación, denominado investigación colaborativa, investigación cooperativa o investigación interactiva. Para los autores, hablar de investigación es hablar en plural, implica rescatar la importancia de generar una tarea cooperativa, el compromiso de un conjunto de docentes que constituyéndose en equipo se disponen a dar lugar al diálogo, al debate, a la búsqueda de puntos convergentes $y$, a su vez, profundizar 


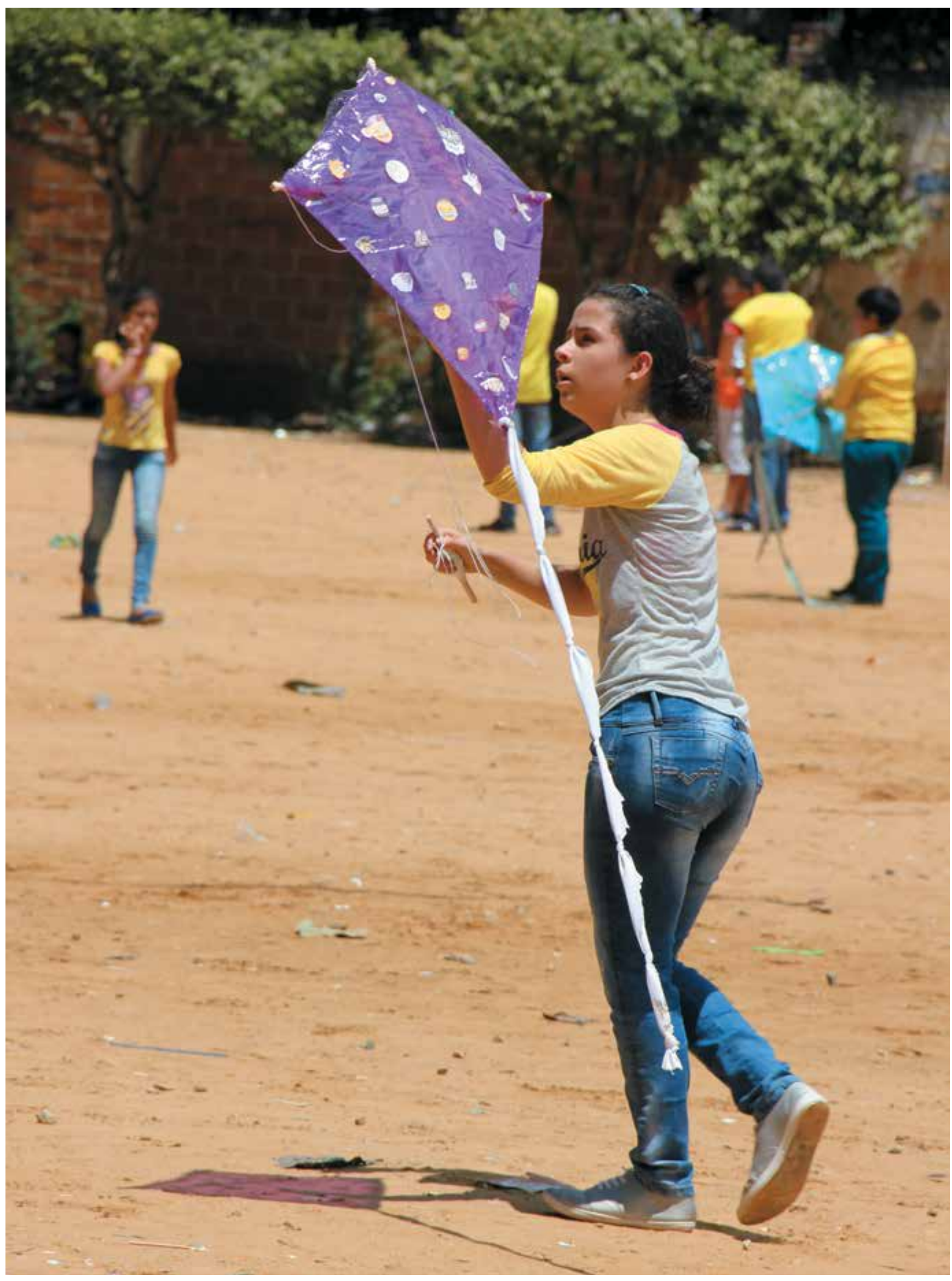


el análisis de aquellos aspectos divergentes (Mandolini, 2006 citado en Enriquez, p. 2012).

Siguiendo con nuestra breve descripción también podemos citar a Dewey (1989) y Schön (1992) quienes incorporan la noción del "docente como profesional reflexivo". Para los autores, el docente debe ser un profesional que reflexiona sobre lo que hace, porque ello le permite un retorno sobre su actividad docente, identificando sus problemas e interviniendo en las diversas situaciones mediante metodologías apropiadas. Así la reflexión se convierte en una fuente inagotable de cambio, porque amplía los niveles de comprensión de la acción educativa, mediante el análisis de las dificultades, el empleo flexible del conocimiento y la búsqueda de nuevas soluciones alternativas a los problemas de la práctica. Es un medio que le permite analizar su práctica y aportar elementos para lograr su mejora.

En un plano más local, latinoamericano, podemos citar los aportes de Freire (1997), entre otros, quienes gestaron e impulsaron la noción del docente-investigador, desde lo cultural, lo participativo, pensando a la investigación como un medio para conocer y resolver los problemas de sus prácticas pedagógicas.

Siguiendo con las posturas que asumen que la investigación es una práctica inherente a la tarea docente, nos parece pertinente el planteamiento de Freire, quien afirma que "no hay enseñanza sin investigación ni investigación sin enseñanza. Esos quehaceres se encuentran cada uno en el cuerpo del otro" (Freire, 1997, p. 30).

Queda claro, entonces, que las propuestas realizadas por varios autores ponen el acento en la importancia que reviste, para los docentes, la práctica investigativa, ya que esta los ubica como protagonistas de sus propias acciones, les permite el desarrollo permanente de conocimientos situados, el análisis y la re- flexión de los contextos educativos en donde despliegan sus prácticas profesionales.

Otras posturas teóricas identifican la investigación y la docencia como dos prácticas diferentes aunque complementarias, pero donde cada una de ellas requiere formaciones y condiciones disímiles. Tal es el planteo de Achilli (2000), quien identifica dos tipos de niveles de investigación, al referirse a la función de la investigación en la formación docente: aquellas que se orientan a contribuir con el avance del conocimiento en un determinado campo de las ciencias sociales, más allá de implicancias prácticas o políticas que este saber genere, y las que denomina investigaciones para, en la medida que buscan concretar una acción en juego. Estas tendrían la finalidad de objetivar la cotidianidad escolar a fin de concretar acciones tendientes a repensar $y$ transformar determinadas problemáticas de la práctica docente.

Otros, en este sentido, distinguen al menos dos tipos de docentes-investigadores. Los que emplean la investigación para construir conocimientos científicos y los que recurren a la investigación para su desarrollo profesional. En este caso, la diferencia estriba en el foco donde ponen la atención. El primero otorga el mismo peso tanto a la creación de conocimientos como a la resolución de los problemas de la práctica; en cambio el segundo, se preocupa esencialmente por la solución de las cuestiones vinculadas al desarrollo profesional y casi no se ocupa de la producción de saberes que tengan validez científica.

Si bien estas clasificaciones pueden parecer esquemáticas, haciendo la salvedad de que no son tipos necesariamente incompatibles, en la medida en que unos y otros buscan más directa o indirectamente mejorar la práctica con base en la construcción de conocimientos, nos permiten poner luz y pensar sobre qué estamos hablando cuando decimos docente investigador o qué tipo de investigaciones propiciamos desde la formación, nos permite ir compren- 
diendo que al hablar de investigación nos referimos a procesos que, aunque no necesariamente contradictorios, se pueden inscribir en registros muy diferentes, teniendo por tanto distintos niveles de impacto en la subjetividad del docente.

Tampoco podemos dejar de mencionar los atravesamientos políticos en los que esta relación se va configurando. En este sentido, sabemos, tal como anticipáramos en la introducción, que el sistema de educación superior es heredero hoy de los procesos de reforma educativa llevados a cabo en los noventa, que significaron una transformación hacia la mercantilización educativa. En este marco, se destacó la figura del docente investigador, se planteó la importancia de educarlo en este sentido desde la formación inicial y en las instancias de capacitación continua, pero esto se inscribió en la lógica de mercado, adquiriendo desde este lugar una significación especial.

Para muchos esto supuso una desvalorización de la práctica docente, que adquiriría mayor legitimidad si incorporaba la práctica de la investigación, enajenándose en un movimiento perverso que colocaba a los docentes detrás de la elaboración de múltiples proyectos, que por otra parte, debían inscribirse en un vocabulario técnico/experto, so pena del temor de "quedar fuera" del sistema. Por otra parte, también es necesario plantear las políticas de investigación que desde los organismos centrales se propiciaron, limitadas en muchos casos a procesos de relevamiento y análisis de información, como insumos para la toma de decisiones políticas, de corto plazo, con altos niveles de burocratización y homogeneización en los estilos de investigación.

Ahora bien, una vez planteado este punto de partida cabe hacerse la pregunta ¿Puede ser el docente un investigador, los procesos de formación lo constituyen como un sujeto investigador? ¿Qué modalidades adoptan los procesos formativos actuales?
Para ahondar en algunos de los interrogantes planteados analizaremos a continuación las orientaciones que han adoptado las políticas educativas nacionales.

\section{Las políticas de formación: un campo de definición de la relación formación docente-investigación}

Historiando el camino de transformaciones que las instituciones de educación superior fueron adoptando, citamos los lineamientos establecidos por la ya derogada Ley Federal de Educación (1993) así como también por la aún vigente Ley de Educación Superior (1995), porque a partir de allí los escenarios de dichas instituciones sufrieron cambios profundos en sus funciones como sus estructuras organizativas.

La Ley Federal de Educación 24.195 estableció un nuevo sistema educativo, y también un nuevo modelo de formación docente: la formación docente continua, que abarcaba entre otros aspectos, la Investigación Pedagógica para el análisis de los problemas emergentes de la práctica en las escuelas.

Como podemos observar, entonces, con la Ley Federal se impulsó al menos en un plano formal, la incorporación de la investigación en las instituciones de educación superior encargadas de la formación docente de todos los niveles educativos. Esta estaba destinada a abordar los problemas emergentes de las organizaciones escolares.

Actualmente, bajo la normativa de la Ley $\mathrm{Na}-$ cional de Educación 26.206 podemos encontrar una línea de continuidad con lo prescrito en las regulaciones anteriores. Se asume que:

La formación docente es parte constitutiva del nivel de Educación Superior y tiene como funciones, entre otras, la formación docente inicial, la formación docente continua, el apoyo pedagógico a las escuelas y la investigación educativa (Ley de Educación Nacional, Capítulo II, artículo 72). 
Otro aspecto importante que se establece, es la creación de un Instituto Nacional de Formación Docente (INFD) que regula las políticas de formación, otorgándole funciones de planeamiento educativo entre los IFD y las instituciones escolares de los diversos niveles educativos. Entre sus funciones se establece "Impulsar y desarrollar acciones de investigación y un laboratorio de la formación" (artículo 76).

Es objetivo del INFD fomentar las investigaciones que integren diversos actores en su implementación, permitiendo el mejoramiento de las prácticas docentes y la gestión institucional (Documento metodológico orientador para la investigación educativa, INFOD, 2013).

Un primer interrogante que surge a partir de la descripción que venimos realizando es, qué relaciones se establecen entre investigaciones y políticas públicas. En los documentos emanados por el INFD observamos una clara intencionalidad de que los resultados de las investigaciones realizadas tengan una incidencia directa en los contextos de trabajo docente. Se plantea de esta manera, que de acuerdo con las conclusiones que cada investigación arroje, el INFOD será el encargado de analizarlas, para proponer cambios necesarios en los contextos de las instituciones educativas de nuestro país.

En el documento metodológico orientador para la investigación educativa (INFD, 2013) encontramos posicionamientos políticos relevantes con relación a las finalidades de la investigación en los institutos de formación. Uno de ellos hace referencia a que el progreso de la investigación educativa en el contexto de los IFD abre la posibilidad de desarrollo de un campo que se construye mediante el análisis y reflexión de las prácticas educativas cotidianas, permitiendo en los docentes-investigadores la profundización de los conocimientos propios de sus disciplinas y de la investigación educativa en particular, así como la actualización de los marcos teóricos que fundamentan las prácticas pedagógicas y didácticas (Documento meto- dológico orientador para la investigación educativa, 2013, p. 216).

Otro de los posicionamientos hace referencia a que los resultados de dichas investigaciones permitirían la resignificación y reconsideración de los contenidos y de las prácticas de formación, así como la instalación de otras formas de vinculación con los saberes resultantes de las prácticas educativas y con el conocimiento, posibilitando la construcción de un marco referencial que acompañe al desarrollo continuo y profesional docente (Documento metodológico orientador para la investigación educativa, 2013, p. 217).

Podemos visualizar con mayor claridad las intencionalidades políticas depositadas en las prácticas investigativas de los IFD; se intenta que los resultados de las investigaciones modifiquen las prácticas de enseñanza y establezcan nuevas vinculaciones con el saber.

En este marco desde el 2007 el INFD viene realizando la convocatoria anual "Conocer para incidir sobre las prácticas pedagógicas", con el fin de regular y promover las prácticas de investigación en los IFD. Como bien señalan Godino y Noriega (2011), los proyectos de investigación integrados en esas convocatorias marcan un hito significativo para los IFD por dos razones fundamentales. En primer lugar, porque influyeron significativamente en las orientaciones de las investigaciones de los institutos y, en segundo lugar, por la posibilidad de desarrollarlas contando la Institución con financiamiento externo.

Al hacer un recorrido por estas convocatorias, podemos decir que en un primer momento estas ponían énfasis en los procesos de enseñanza y de aprendizaje en las diversas áreas del conocimiento. Podríamos anticipar y señalar que en ellas se vislumbra una concepción de la investigación como herramienta de resolución de problemas que se presentan en la vida escolar. Este tipo de investigaciones serían aquellas 


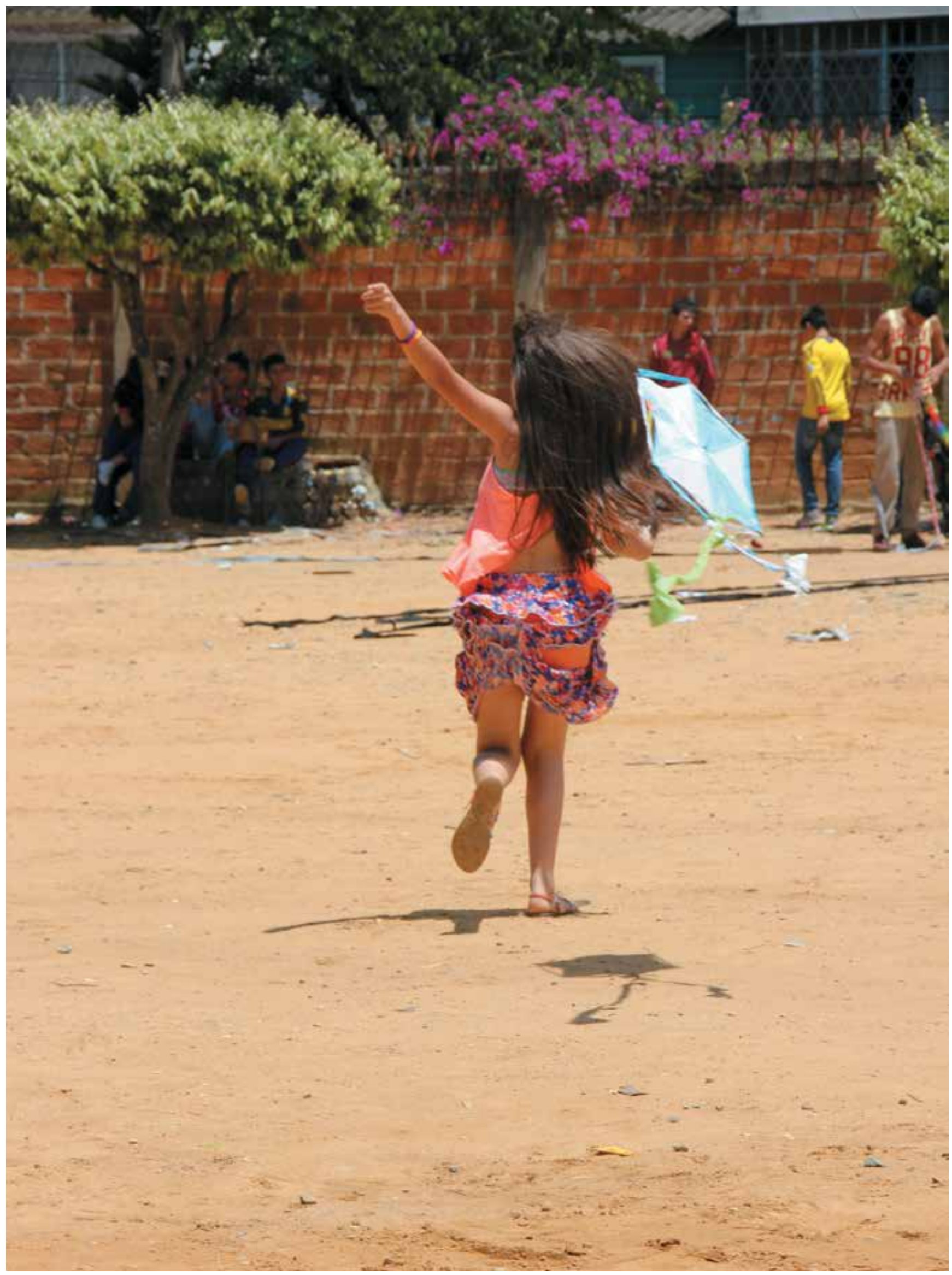


que Achilli (2000) llama estudios orientados para concretar acciones tendientes a repensar o transformar determinadas problemáticas del quehacer escolar, diferenciándola de las investigaciones orientadas a desarrollar aportes a un campo determinado de las ciencias sociales, más allá de las implicancias prácticas/ políticas.

Si bien hay una continuidad en esta manera de concebir la investigación en la formación, observada en la conservación misma del nombre de la convocatoria, Conocer para incidir sobre las prácticas pedagógicas, a partir del 2010 las temáticas se fueron ampliando hacia nuevas áreas, tales como: análisis de experiencias de innovación, análisis de las condiciones institucionales que inciden en la relación entre sujetos individuales y colectivos, multiculturalismo, estudios sobre las nuevas tecnologías de la información, problemas de exclusión e inclusión, políticas públicas. También continuaban las temáticas vinculadas a la enseñanza y al aprendizaje en relación con el contenido disciplinar.

Podemos decir entonces, que se incorpora una mirada más holística de la problemática educativa desde el INFD, puesto que aparecen como objeto de interés no solo lo que acontece en el aula, sino los complejos procesos de vinculación de la escuela con otros actores, organizaciones e instituciones sociales, así como la misma dinámica institucional (Godino y Noriega, 2011).

\section{La investigación en el Instituto de Formación Docente San Luis}

El Instituto de Formación Docente Continua, San Luis (IFDC SL) surge en medio del proceso de transformación educativa que caracterizó la década de los noventa. Su creación fue un hecho distintivo si se la compara con el proceso iniciado en el resto de las provincias. Mientras estas desarrollaban políticas que tendían a transformar las instituciones terciarias en función de las nuevas regulaciones, en 1998 en
San Luis se llevó a cabo un proceso de cierre de todas las instituciones de formación terciaria de la provincia, para abrir en 1999, por medio del Decreto No 3119/99- MGYE, dos institutos, uno en San Luis y otro en Villa Mercedes. Estos se convertirían en los polos formadores de docentes para toda la provincia y asumían, en su configuración, los principios de la reforma educativa planteada por la Ley Federal de Educación 24.195 y la Ley de Educación Superior 24.521.

En este sentido, desde la definición del perfil del egresado expresada en el Proyecto Educativo Institucional (PEI), aparece una concepción de la enseñanza asociada con la actividad investigativa:

la formación del profesor busca la autonomía profesional desarrollando su conocimiento pedagógico en el proceso de construcción y reconstrucción de las reflexiones sobre situaciones prácticas reales que tengan como punto de referencia las competencias que se encuentran subyacentes en las prácticas profesionales.

Y más adelante:

finalmente, (la naturaleza práctica del saber pedagógico), requiere la sistematización y el distanciamiento en un momento posterior, para poder objetivarla, tomándola como una cosa sobre la cual se puede pensar en forma fundamentada...(PEI, IFDC SL, 2000, p. 7).

En el mismo documento, el IFDC prevé cumplir de manera articulada en el mismo programa de desarrollo institucional, con las tres funciones establecidas por la Ley de Educación Superior: la formación docente inicial; la capacitación, perfeccionamiento y actualización docente; y la de investigación, en pos de una formación profesional para el desarrollo de una praxis, en la que se integran contenidos teórico prácticos.

En el plano formal, tal como lo establece el $\mathrm{PEl}$, estas funciones fueron pensadas de tal forma, para que se articulen y complementen en las siguientes interacciones: 
- La investigación acción como contenido de la formación inicial.

- La formación inicial que en sí misma es ámbito de investigación.

- La investigación como instancia que señala rumbos para la formación inicial.

- La formación inicial que genera preguntas de investigación que alimentan los procesos de capacitación.

- La capacitación como objeto de investigación.

- La investigación evaluativa como orientadora de las ofertas de capacitación.

También desde el PEl, se establecen lineamientos respecto de la función de investigación. Se habla de investigación educativa, entendiendo por esta aquella que está dirigida a la búsqueda sistemática de conocimientos, con el fin de que sirvan de base para la comprensión de los procesos de enseñanza y de aprendizaje, así como para la mejora de la formación profesional. Además, se hace alusión a la investigación y al desarrollo, poniendo el énfasis en los procesos de innovación que se espera provea la investigación. Finalmente, se concibe a la investigación en la acción como una estrategia especialmente favorable, en la medida que integra los procesos de investigación a la acción educativa.

Se establece también en el PEl, el encuadre que tendrán las investigaciones en el IFDC SL. Estas se canalizarán a través de proyectos que presentarán los equipos docentes a la dirección académica y de extensión, que serán las unidades encargadas de evaluar y gestionar la implementación de los proyectos. Dos elementos se señalan como relevantes a la hora de constituir los proyectos: la conformación de equipos de investigación multidisciplinarios y la participación de estudiantes en formación.

\section{El desarrollo de las investigaciones en el IFDC SL}

Nos interesó conocer también de qué manera estas políticas educativas e institucionales impactaron en la realización efectiva de proyectos de investigación en el IFDC SL y qué elementos operaron y operan como facilitadores y obstaculizadores o simplemente como configurantes de las prácticas de investigación llevadas a cabo en la Institución.

En el marco de esta investigación, Godino y Noriega (2011) realizaron un relevamiento de los proyectos de investigación llevados a cabo en la Institución desde sus comienzos. Destacan que en los primeros años de vida del Instituto, no se registraron acciones de investigación. Esto es, la Institución no guarda registro de las acciones de investigación llevadas a cabo en estos primeros años. Sin embargo, los docentes informan que desde el comienzo existieron iniciativas de investigación, así como seminarios y talleres de formación en el campo de la investigación que no tuvieron sistematicidad ni permanencia en el tiempo. Los docentes manifiestan también que estas inquietudes surgían de los grupos docentes, pero no constituían una prioridad institucional.

Desde estas instancias fueron apareciendo las primeras tensiones en la definición de la función y el tipo de investigación que se debía privilegiar en el Instituto. Dos posturas se destacaban: por un lado, quienes sostenían que la investigación se debía orientar al sistema educativo provincial en sus distintos niveles $y$, por el otro, quienes sostenían que se debía orientar a las áreas disciplinares de la formación que por entonces eran historia, ciencia política e inglés.

A partir del año 2006, las actividades de investigación tomaron rumbos diversos y se iniciaron indagaciones significativas en problemáticas educativas de la provincia (Godino y Noriega, 2011). 
La experiencia del taller "la investigación sobre la formación docente en San Luis. Aspectos abordados y estado de situación". Un espacio de reflexión colectiva

En el marco de las actividades del proyecto de investigación se realizaron en el mes de setiembre de 2011, las "I Jornadas de Formación Docente y Educación Primaria sobre Comunicación, Instituciones y Ciudadanía, en Territorios Marcados por la Desigualdad Social". Las mismas tuvieron como objetivo consolidar un espacio de trabajo en red entre los miembros de los institutos de formación docente y universidades nacionales, vinculados al estudio de la formación docente.

En el marco de las jornadas se llevó a cabo el taller"La Investigación Docente en San Luis. Aspectos Abordados y Estado de Situación", que pretendía indagar en la temática específica de la relación investigación/formación docente.

El propósito del taller fue generar un espacio de reflexión y diálogo sobre las relaciones y tensiones posibles entre formación docente e investigación. En el taller participaron docentes de las carreras de Profesorado de los institutos de Formación Docente de San Luis y de Villa Mercedes, docentes de nivel primario y secundario del Sistema Provincial, alumnos de las carreras de Profesorado de ambos institutos, alumnos de la universidad y los miembros del proyecto de Investigación en Red.

En el primer momento del taller el equipo coordinador presentó al grupo una sistematización realizada sobre las temáticas abordadas en los trabajos de tesis de grado y posgrado vinculados a educación de la Facultad de Ciencias Humanas de la Universidad Nacional de San Luis y los trabajos realizados en el Instituto de Formación Docente San Luis.

Luego, se organizó el trabajo por grupos de cinco personas aproximadamente para que a partir del planteamiento de ejes orientadores, compartan sus posicionamientos respecto a la relación investigación/formación, a las condiciones y a las razones por las cuales se investiga $y$, finalmente, a las áreas de vacancia en la investigación educativa.

Algunas de las conclusiones a las que se arribaron fueron:

\section{- Respecto de la relación investigación/ formación}

En la socialización de lo trabajado, los grupos plantearon que efectivamente existe relación entre docencia e investigación (Vaillant, 2007; Enriquez, 2012). En palabras de un docente:

Es impensable que ambas (investigación y formación) no se den de manera conjunta (docente del Campo de la Formación General, Profesorado en Educación Primaria, $2^{\circ}$ año).

Según ellos, la mayoría de los problemas de investigación surgen de la práctica docente (INFD, 2009), con el fin de generar insumos para su mejora y resolver algún problema de la realidad educativa.

Investigaciones realizadas por Soria, Anquín y Bellavilla (2011) dan cuenta de la importancia que tiene partir de las problemáticas concretas que plantean las prácticas pedagógicas y docentes. Los resultados de dichas investigaciones ponen en evidencia, la manera en que se puede retroalimentar la investigación y la formación docente, consideradas como momentos constructivos de nuevos conocimientos prácticos situados.

Otro de los grupos también señaló que la investigación es una manera de superación para el propio docente, ya que colabora a "dotar de profesionalismo" la tarea (Vaillant, 2007).

En el marco de la reforma de las carreras docentes actuales (entre ellas la incorporación de la investigación como acción inherente a la práctica) existe un predominio por una formación que desarrolle posicionamientos (Vassiliades, 2012) tendientes a visualizar la acción polí- 


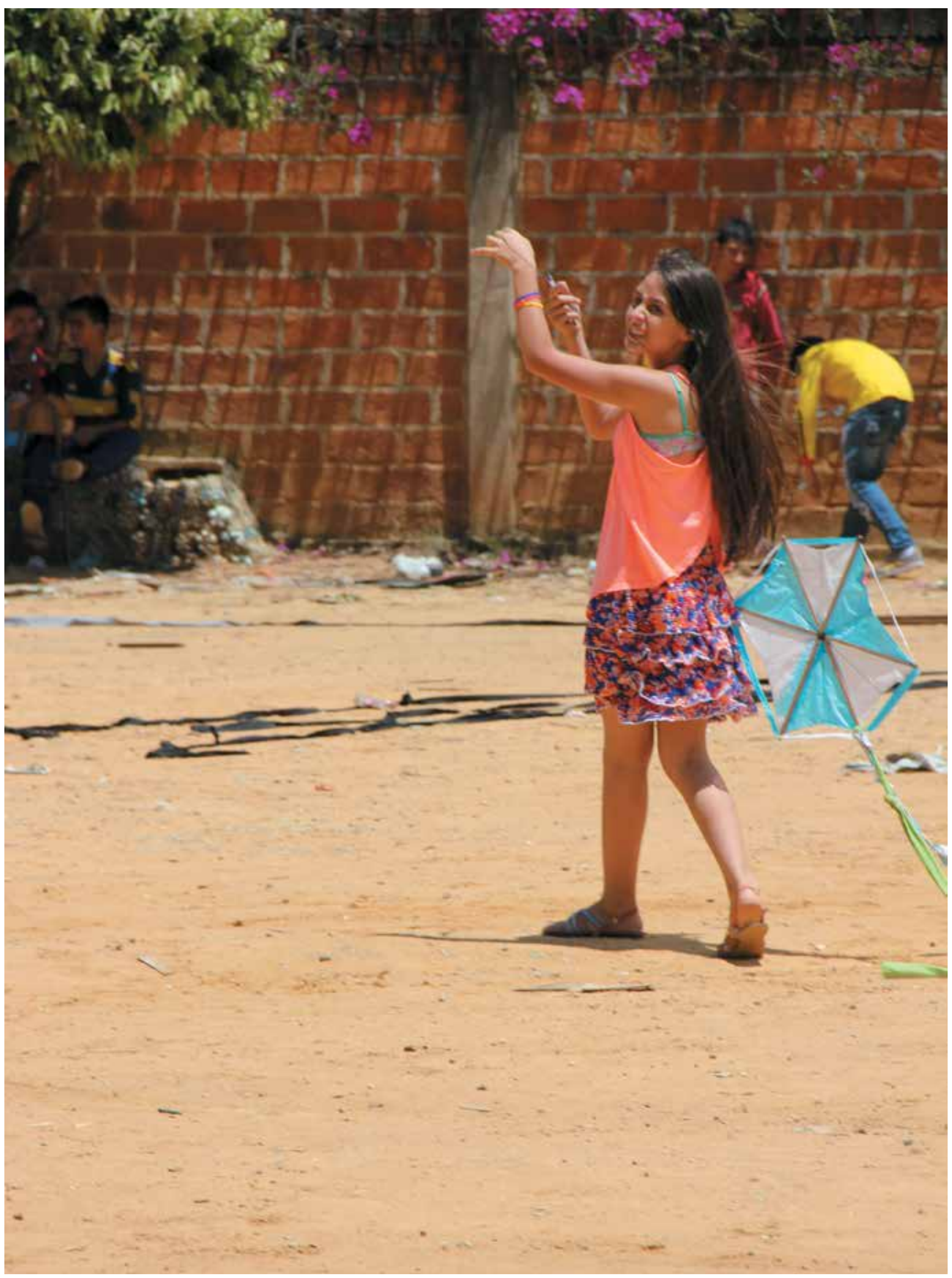


tica de la docencia (Ferry, 2008). Por ende, desde esta perspectiva (no lineal, ni conflictiva) al docente se le atribuye la acción transformativa de los escenarios educativos. Podemos hacer hincapié en que este hecho representa verdaderamente un cambio relevante, al menos en el plano ideológico.

Los docentes formadores expusieron claramente durante el taller que ellos colaboran con formar "otro docente", comprometido con su realidad social, productor de conocimiento y protagonista esencial en las instituciones educativas. Esta mirada marca una ruptura epistemológica con relación a la formación docente desarrollada a partir de las históricas tradiciones formativas (modelo academicista y técnico), ya que se piensa en un docente comprometido con su realidad y coprotagonista (junto a colegas, alumnos) de los cambios que puedan irrumpir en las culturas institucionales (Ball, 1989; Rockwell, 2000; Ferry, 2008).

Los alumnos a su vez, manifestaron que si bien saben que existen investigaciones en curso en el Instituto, no conocen bien su temática,

Las investigaciones están como camufladas, uno no sabe sobre qué se está investigando con claridad, aunque a veces incluso participamos en algunas de ellas (alumna de $2^{\circ}$ año de Profesorado en Educación Primaria).

También expresan que a pesar de que les interesaría implementar ese "hábito", podríamos decir reflexivo (Giroux, 1984), sienten que al menos durante los primeros años de la carrera, aún no están capacitados para esto, quizá porque en la Institución formadora la investigación no hace parte de la cultura formativa (Sarlé, 2007; Noriega, 2009; Godino y Noriega, 2011).

En la experiencia se visualiza la transformación de la formación docente actual en los IFDC. Avance reflejado en la presencia de paradigmas complejos que permiten analizar teóricamente realidades; en la actualización de contenidos presentes en los nuevos y renovados planes de estudio de las carreras docentes; en la presencia de los perfiles profesionales con una sólida formación académica (estudios universitarios de grado y posgrado).

Ahora bien, creemos que estos avances todavía no van acompañados de acciones que tiendan a la producción de conocimientos relacionados con las realidades educativas de la provincia. Es decir, existen escasas experiencias en las que se han podido gestar instancias de 'acercamiento' desde el IFDC hacia las escuelas del nivel primario. En algunos casos, a través de experiencias esporádicas a partir de visitas a las escuelas en el marco de alguna materia (por lo general, desde el espacio de Práctica), también desde instancias de investigaciones tendientes a develar situaciones educativas del nivel o en instancias de capacitación generadas desde el IFDC.

Un grupo de docentes y alumnos del IFDC de Villa Mercedes relató que, en dicha Institución, los alumnos cursan y aprueban las materias vinculadas a investigación, participando en ese lapso de tiempo, al menos en alguno de los proyectos de investigación de la Institución, y esto obedecería al criterio de que investigar se aprende investigando (Rigal y Sirvent, 2011; Soria, Anquín y Bellavilla, 2011).

Respecto de esto último, surgió otra manera de entender el problema, que posiciona a la investigación como una actitud crítica hacia el saber (Ferry, 2008), que desborda la disciplina y constituye en tanto una transversalidad, que no se tiene que dar necesariamente en una investigación en marcha.

\section{- En relación con las condiciones en las cuales se investiga}

En la cultura institucional del IFDC se identifican elementos que actúan como obstaculizadores para el desarrollo de experiencias de investigación sistemáticas que propician conocimientos enriquecedores. En palabras de los formadores: 
No hay demasiado apoyo institucional en materia de investigación. No sé cómo han hecho los docentes disciplinares. Conozco algunos docentes que han seguido investigando (...) Hay docentes fundadoras que han ido haciendo investigaciones y han ido incorporando gente nueva, pero no han podido sostenerlas (docente del Campo de la Formación General y Específica, $2^{\circ}$ año de Profesorado en Historia, nivel secundario y Profesorado en Educación Primaria).

Bueno, creo que la investigación es la pata floja de esta Institución. No tiene que ver con que sus docentes no investigan, porque todos lo hacen. No ha habido esta posibilidad de articular esas investigaciones con la Institución. Es un saber importante, requiere mantener en el tiempo las prácticas de investigación (docente del Campo de la Formación General y Específica, $2^{\circ}$ año de Profesorado en Historia, nivel secundario).

Podemos sostener que el 'lugar' que ocupa la investigación en el IFDC, tanto en la actualidad como en sus inicios, se relaciona profundamente con los diversos posicionamientos epistemológicos que sustentan los miembros de la Institución. Es decir, no hay acuerdos aún sobre qué finalidades deberían sostener los procesos investigativos llevados a cabo por los equipos docentes del Instituto. Encontramos en los discursos de los formadores perspectivas diversas sobre qué significa investigar en el Instituto de Formación Docente Continua.

Para algunos profesores la investigación es 'inherente' a la práctica docente, por ende, investigar y enseñar pueden desplegarse casi al mismo tiempo. Esta concepción se acerca más a los planteos de Schön (1992) en relación con la "reflexión en la acción".

Con respecto a las prácticas de investigación los docentes formadores expresan sentimientos de incertidumbre, ya sea por la inexistencia de una direccionalidad u orientación para el desarrollo de proyectos de investigación en el IFDC; por las dificultades que se presentan en el momento de formar equipos de investigación que puedan sostenerse en el tiempo; por la inexistencia de financiamiento; por las excesivas demandas que reciben algunos docentes en relación con sus otras dos funciones (formación inicial y capacitación) y quizá también por la escasa claridad de las finalidades de los procesos de investigación.

Muchos sentimientos se generan en el IFDC a partir de la "obligatoriedad de la investigación". Para algunos formadores el carácter de obligatorio, condiciona las dinámicas de la Institución, conformándose, muchas veces, grupos de trabajo que responden más a exigencias institucionales que a verdaderos intereses de investigación. En el siguiente fragmento podemos observar lo expresado por un docente formador:

Me parece que algunas son importantes, pero en muchos casos estamos en algo ni convencidos, ni sabiendo la importancia de ese proyecto. Estamos porque sabemos que es uno de los requisitos que nos van a pedir a la hora de revalidar (docente del Campo de la Formación Específica, 3er año Profesorado en Historia, nivel secundario y Profesorado en Educación Primaria).

Otros docentes analizan las dificultades institucionales para la generación de prácticas de investigación. Las mismas hacen alusión a los inconvenientes para armar equipos de investigación basados en las diversas trayectorias formativas de los docentes, a los problemas que se presentan para definir líneas o temas de investigación de interés general y a la sobrecarga de tareas que tienen algunos docentes:

Se supone que tiene que ser un $30 \%$ de la carga horaria de cada uno de nuestros cargos. Es muy difícil de lograr porque no hay grupos de investigación armados (docente del Campo de la Formación Específica, 3er año de Profesorado en Educación Primaria y Profesorado en Lengua, nivel secundario).

A pesar de las dificultades mencionadas, existen en el IFDC varias experiencias de investigación iniciadas por los docentes, con base en problemas o temas que ellos han observado como relevantes: 
Nosotras empezamos a hacer una investigación este año. Es sobre los ingresantes. Tratamos de estar docentes del primer año de todas las carreras porque la investigación abarca a todos los alumnos ingresantes. Un poco lo que nos llevó a realizar esta investigación fue ver por un lado, el alto grado de abandono, de desgranamiento de los alumnos, y por otro lado, el haber escuchado en el trayecto de ingreso a docentes responsabilizar o culpabilizar a los chicos el abandono de la carrera (...) La información obtenida nos saca un velo sobre los alumnos (docente del Campo de la Formación General, $1^{\circ}$ y $4^{\circ}$ año de Profesorado en Educación Primaria y Profesorado en Historia, nivel secundario).

Un aspecto que se destaca en las narraciones de los docentes formadores es la ausencia de financiamiento para el despliegue de investigaciones. La Institución no apoya económicamente las iniciativas investigativas. Quizá por tal razón desde las posturas de algunos docentes se sostenga la idea de investigar su propia práctica docente: "reflexionar en la acción" (Schön, 1992):

Tampoco la gestión directiva apoya los proyectos de investigación que se inician (docente del Campo de la Formación General, 3er año de Profesorado en Lengua, nivel secundario y Profesorado en Educación Primaria).

Desde la Institución tampoco creo que se fortalezcan las prácticas investigativas. Porque existe escaso o nulo financiamiento, no hay reconocimiento ni validación de jurados externos a la Institución (docente del Campo de la Formación General, 1er año de Profesorado en Educación Primaria).

Yo he ido 'picoteando' en investigaciones. No he podido mantenerme en investigaciones del IFDC por diferentes razones. Una de las causas fue que cada vez que yo me incorporaba a una investigación iba como cerrándose y se focalizaba hacia otros ámbitos (docente del Campo de la Formación General, $2^{\circ}$ y $3 e r$ año de Profesorado en Educación Primaria).

Los fragmentos de las narraciones de los docentes ilustran una cultura institucional que 'relee' sus prácticas de formación desde posicio- namientos enfrentados. Algunas miradas se encuentran en acciones compartidas en cuanto a los alcances que se le depositan a las prácticas de investigación relacionadas con la comprensión de escenarios educativos complejos; al acercamiento interinstitucional para la mejora de la formación inicial; a la conformación de equipos de trabajo que colaboren para reforzar prácticas integradas, entre otras.

De modo contrario, otras miradas evalúan las prácticas de investigación como carentes de sentido en el marco de las características de la cultura del IFDC. Esta perspectiva se refuerza cuando evalúan el alcance de las producciones logradas a partir de prácticas de investigación desarrolladas en el Instituto. La investigación es reposicionada como una de las funciones que el Instituto le atribuye a los docentes formadores, como inherente a una cultura de producción y de circulación de conocimientos. En dicho contexto, la investigación está atravesando un período de redefinición de sentido, circunscrito a las características institucionales del IFDC.

En diversos casos, la culminación de proyectos de investigación financiados, ha ocasionado la interrupción de procesos de formación, investigación e intervención que requieren de tiempo para su consolidación. Así, también, el retiro del financiamiento produjo la desarticulación entre las instituciones con las que se investiga y la Universidad, haciendo que los logros alcanzados se desvanezcan con el tiempo (Soria, Anquín y Bellavilla, 2011).

\section{- Respecto de las razones por las cuales se investiga}

Algunos mencionan la responsabilidad del "propio ser docente", en la medida que la investigación mejora la propia práctica. En este ámbito, el docente-investigador es un profesional que reflexiona sobre lo que hace, se replantea su accionar, y acostumbra revisar sus experiencias y actuaciones con el propósito de aprender (Latorre, 1992, citado en Enriquez, p. 2012). 


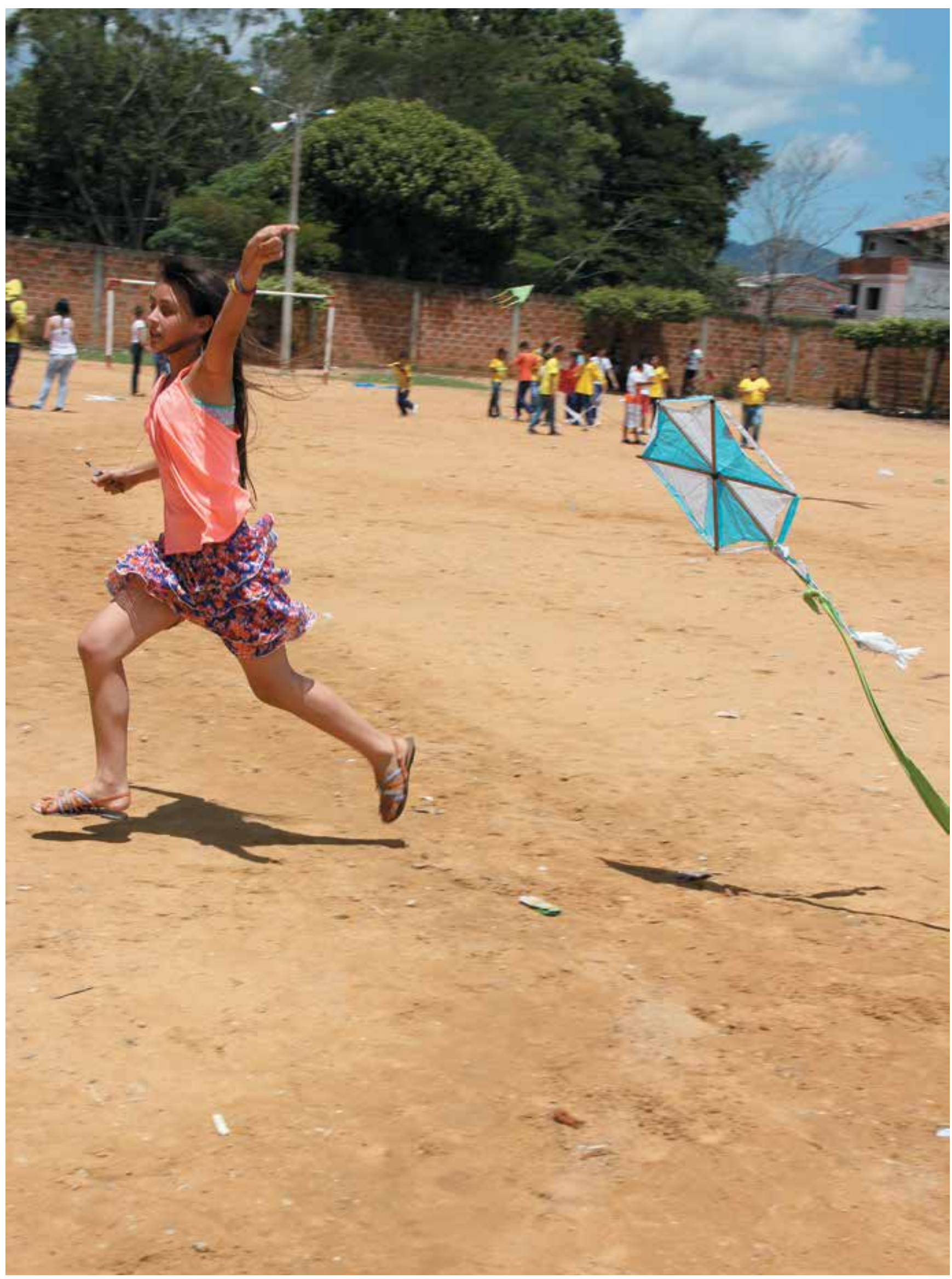


Otros plantean la necesidad de la investigación, por la distancia que encontraron entre la formación y los escenarios reales. En este marco de discusión surgió nuevamente el tema de las condiciones bajo las cuales se investiga. En este sentido, una docente de nivel primario señaló que esta es una discusión que se encuentra bastante lejana de su realidad:

Acá (escenario de la jornada) se plantean discusiones respecto de si hay tiempo o no, si hay financiamiento o no, pero para nosotros, ¿dónde queda la investigación, cómo quedamos ubicados los docentes de primaria en este tema?" (docente egresada del IFDC SL, profesora de Educación Primaria).

Esto llevó a plantear que la investigación sigue siendo una función de elite, jerárquica; situación que en un sentido se asocia a la rigurosidad y validez, pero que a su vez la aleja de ser una práctica accesible a todos. El fragmento citado nos permite pensar también qué alcances tiene en la formación docente inicial, las nuevas configuraciones que se construyen alrededor de la figura del docente-investigador (de todos los niveles escolares).

En este marco, también emergió la pregunta: “Para quién se investiga?". Algunos destacaron la importancia de no olvidar qué se investiga para mejorar la realidad del alumno, qué es en definitiva la propia realidad y que esto haría de la investigación una praxis. Otros señalaron que en las actuales condiciones muchas veces esto se desdibuja y se termina investigando para la misma estructura (la universidad, los institutos), para cumplir con la función, para continuar percibiendo incentivos, etc. En definitiva, se trata de un posicionamiento político (Documento del INFD, 2013).

\section{- Las áreas de vacancia en la investigación educativa}

Los grupos coincidieron en que se investiga mucho en problemáticas ligadas a la práctica áulica, pero no se abordan problemáticas vin- culadas a la macro política, a lo organizacionalinstitucional, a la problemática de los alumnos en formación, a la circulación y validación que tiene el conocimiento que se produce. Respecto de esto último, se planteó también, la baja circulación que tiene el conocimiento que se produce y el bajo impacto transformador.

En este sentido, se observaron diferentes posturas de los docentes de los institutos; algunos señalan la necesidad de focalizar la mirada en investigaciones vinculadas a la organización institucional, a la política, a la micropolítica (Ball, 1989), mientras que otros, en los problemas específicos de la práctica docente.

Tal vez, es pertinente aquí hacer nuestro el desafío que plantea Sousa Santos, citado por Yuni (2009), acerca de reflexionar sobre las "ausencias del pensar" en relación con un tema, sugiriendo mirar esas ausencias no como un descuido epistémico o como el producto de una valoración de irrelevancia, sino como la resultante de un proceso ideológico de neutralización del conflicto potencial que implica retomar el cuestionamiento de esas preocupaciones.

\section{Conclusiones}

Existe una clara intencionalidad política de instalar la investigación en los institutos, hecho reconocido por docentes como inédito y relevante, como así también una cierta idea de darle carácter universitario, lo cual estaría asociada a la calidad de las prácticas y productos de la investigación. Bajo esta impronta se vienen desarrollando desde el INFD y el FONCyT (organismo de financiamiento) distintos programas de investigación, en su mayoría concursables, a los cuales los institutos de formación docente se presentan.

Sin lugar a dudas, estos "nuevos vientos", se constituyen en futuros temas para incluir en la agenda de las investigaciones por emprender en torno a las políticas que se formulan y 


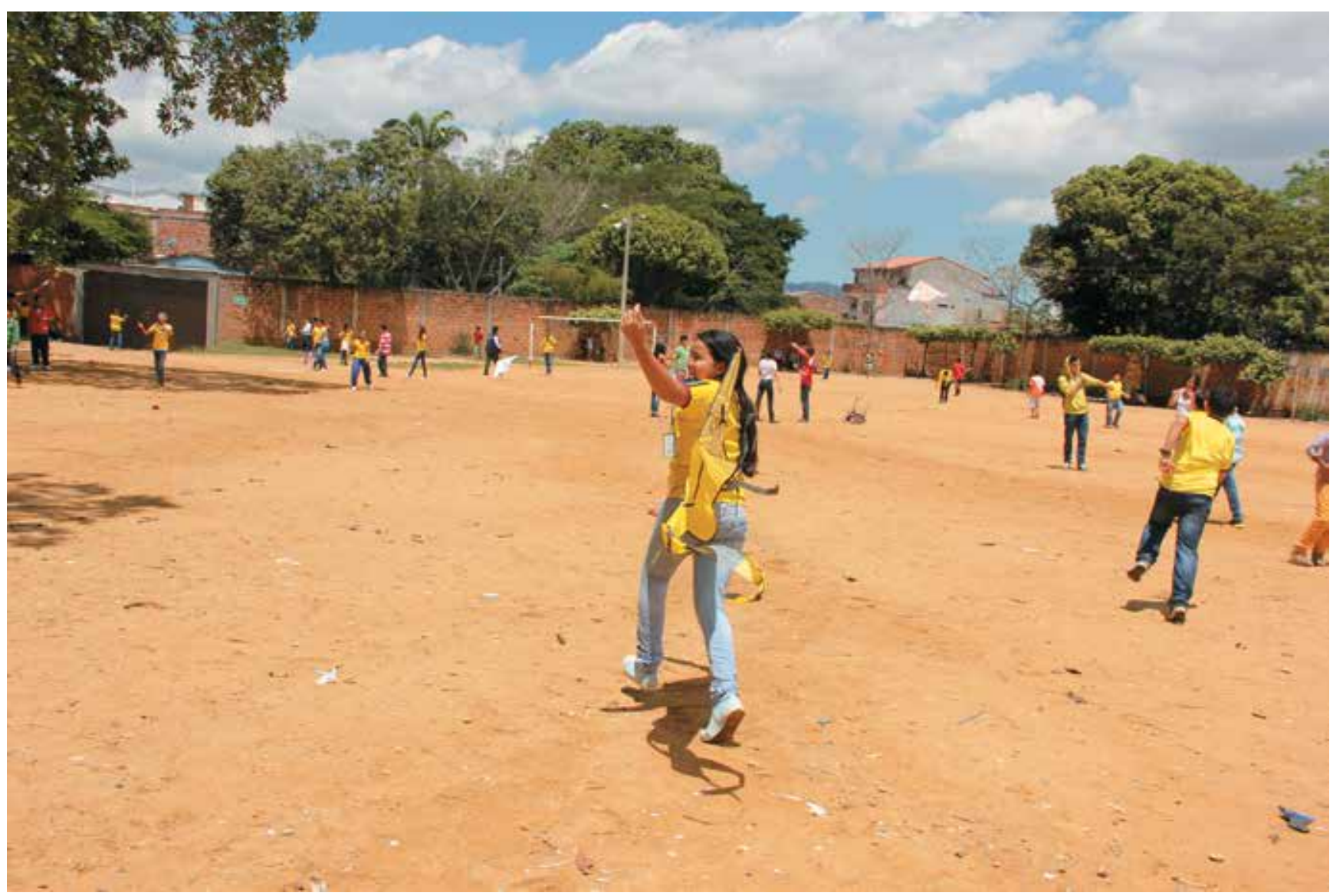

su impacto en las instituciones y sujetos que las habitan, o al decir de Ball (1989) indagar -a partir de una "teorización combinada"-, el proceso político y los efectos de la política. En este sentido, intentamos aproximarnos desde el taller, a esta "teorización combinada", iniciando la búsqueda acerca del lugar otorgado por los docentes formados y en formación, a la investigación, tanto en la formación inicial como en el desarrollo profesional.

Es sumamente relevante que se generen políticas educativas en relación con la formación docente respaldadas en los avances de las investigaciones vigentes. De modo contrario, se estarían fortaleciendo dos agendas paralelas, una relacionada con la agenda de la investigación, que intenta describir, interpretar y proponer alternativas en función de sus resultados, y otra proveniente de los sectores de gestión política que generan y aplican regulaciones al sistema educativo y a las instituciones escola- res de nuestro país desatendiendo las diversas realidades socioeducativas.

Somos testigos del gran deterioro que ha sufrido la educación en estas últimas décadas, flexibilidad, fragmentación, reformas han invadido nuestra cotidianeidad. En este momento también estamos viviendo una gran transformación del sistema educativo, del sistema de formación docente, del currículo de formación. Por ello, podemos hablar de la construcción de nuevas identidades docentes, debido a los cambios producidos, tanto en las políticas educativas (en el ámbito nacional y provincial), como en las estructuras sociales.

Rescatamos las posiciones teóricas que respaldan la figura del docente, investigador de su propia práctica pedagógica. Compartimos los aportes de Stenhouse, Hopkins, Dewey, Freire, en relación con que el docente es el sujeto que se encuentra en mejores condiciones de captar las visiones y preocupaciones de la vida insti- 


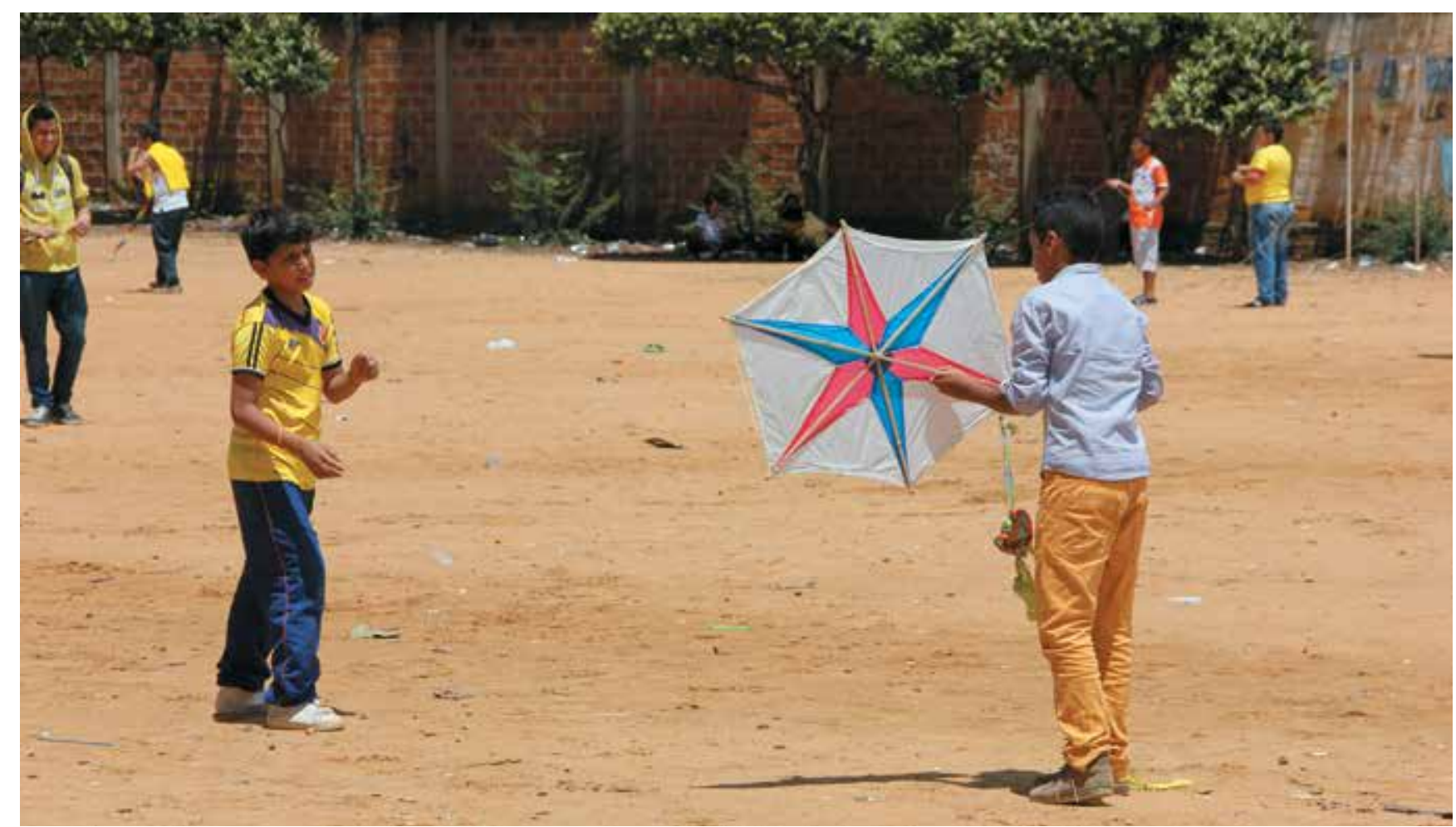

tucional y áulica. Ahora bien, este impulso a la investigación generado en las últimas décadas, viene acompañado por un lado de estas posturas teóricas que bregan por la'profesionalización del docente', pero por otro, no se han generado con la misma magnitud cambios en las condiciones estructurales del trabajo docente, como así tampoco en los trayectos de formación de las instituciones de educación superior, que permitan que la investigación como práctica específica relacionada pero a la vez separada de la enseñanza, se desarrolle en el sentido que las políticas públicas impulsan.

Deseamos rescatar, además, la importancia que reviste la incorporación de los docentes a los procesos investigativos, para que paulatinamente puedan ir apropiándose de los conocimientos disponibles en los campos científicos, como así también enriquecerlos con los conocimientos 'situados', que puedan desarrollarse en las comunidades docentes que se construyan bajo las iniciativas políticas actuales. Asimismo, dejamos sentado las dificultades que reviste el crecimiento de las prácticas de investigación en las instituciones educativas del nivel supe- rior no universitario, y mucho más aún en las instituciones de los otros niveles educativos (primario y secundario).

La posibilidad de habilitar espacios de encuentro para la reflexión, el diálogo y la construcción de conocimiento en torno a la formación docente, entre los diversos actores que desde un lugar u otro participamos en este proceso, en definitiva facilita el empoderamiento sobre los propios actos, es decir, la apropiación del poder que se tiene sobre ellos y por tanto de su poder transformativo.

Por otra parte, creemos también, que más allá de la construcción de conocimiento, el proyecto de investigación en red posibilitó recuperar las voces de los actores mismos; alumnos en formación, docentes del nivel, docentes formadores, directivos. Pensamos, con Cullen (2009), que uno de los fenómenos esenciales de nuestra época es la retirada de la palabra, crisis en definitiva de la posibilidad de pensar la realidad. Por eso, la recuperación de esta es una tarea fundamental para quienes trabajamos en torno a la formación docente. 


\section{Referencias bibliográficas}

Achilli, E. (2000). Investigación y formación docente. Argentina, Entre Ríos: Laborde Editor.

Apple, M. W. (1989). Maestros y textos. Una economía política de las relaciones de clase y de sexo en la educación. Madrid: Paidós/MEC. Temas de Educación.

Ball, S. (1989). La micropolítica de la escuela. Hacia una teoría de la organización escolar. Madrid: Paidós/MEC.

Bartolomé M., Anguera, T. (1990). La investigación cooperativa: vía para la innovación en la universidad. Barcelona: Promociones y Publicaciones Universitarias.

Corti, A. (2013). La investigación en red en el nivel superior mediante diseños colaborativos basados en la reflexión situada. En Cadaviera, G. y Ramallo, F. (comp.). Narrativa(s), práctica(s) e investigación(es). Mar del Plata: Universidad Nacional de Mar del Plata.

Cullen, C. (2009). Entrañas éticas de la identidad docente. Buenos Aires: La Crujilla.

Davini, C. (1995). La formación docente en cuestión: política y pedagogía. Buenos Aires: Paidós.

Dewey, J. (1989). Cómo pensamos. Barcelona: Paidós.

Dabin y Calafato, A. (2005). Significados de la docencia en ingresantes y profesores: puntos de encuentro y desencuentro. Recuperado de www.ucc.edu.ar/paginas/ encuentros2005/dabincalafatol.pdf

Documento del INFD (2013): La organización de la función de investigación en la formación docente. Versión para la discusión Área de Investigación. Dirección Nacional de Formación e Investigación. Recuperado de: http:// www.cedoc.infd.edu.ar/.../La_organizacion_de_la_funcion_de_investigacion

Enriquez, P. (2012). El docente investigador: un mapa para explorar un territorio complejo. [Versión electrónica]San Luis: Laboratorio de Alternativas Educativas. Facultad de Ciencias Humanas. Universidad Nacional de San Luis.

Ferry, G. (2008). Pedagogía de la formación. Buenos Aires: Facultad de Filosofía y Letras y Ediciones Novedades Educativas. Colección Formación de Formadores.

Freire, P. (1997). Pedagogía de la autonomía. México: Siglo XXI.

Giroux, H. (1984). La educación pública y el discurso, el poder y el futuro. Revista de Educación, 274, pp. 5-24. Recuperado de: http://www.mecd.gob.es/revistade-educacion/numeros-revistaeducacion/numerosanteriores/1984/re274/re274_01.html
Godino, C. B. y Noriega, J. (2011). La investigación educativa en la formación docente. Análisis de un caso. Ponencia presentada en las VI Jornadas Nacionales sobre la Formación del Profesorado. Universidad Nacional de Mar del Plata. Recuperado de http://www.mdp.edu. ar/humanidades/pedagogia/jornadas/jprof2011/comunicaciones/146.pdf

Hopkins, D. (1989). Investigación en el aula. Guía del profesor. Barcelona: Promociones y Publicaciones Universitarias.

INFD/ MECyT (2007) "Lineamientos Nacionales para la Formación Docente Continua y el Desarrollo Profesional" Res.30/07 Anexo II, Buenos Aires.

INFD/ MECyT (2007). "Plan Nacional de Formación Docente" Res. 23/07. Buenos Aires.

Instituto de Formación Docente San Luis (2000). Proyecto Educativo Institucional. San Luis.

Ley de Educación Nacional № 26.206. Recuperado de http://portal.educacion.gov.ar/consejo/files/2009/12/ley_de_educ_nac1.pdf

Ley de Educación Superior № 24.521. Recuperado de http://www.me.gov.ar/consejo/cf_leysuperior.html

Ley Federal de Educación № 24.195. Recuperado de http://www.me.gov.ar/consejo/cf_leyfederal.html

Miranda, E. (2011). Una caja de herramientas para el análisis de política educativa. La perspectiva de los ciclos de la política (Policy Cycle Approach). En Miranda, E. y Bryan, N. (Eds.). (Re) pensar la educación pública. Aportes desde Argentina y Brasil. Córdoba: Editorial de la Facultad de Filosofía y Humanidades/UNC.

Noriega, J. (2009). Identidad profesional docente. Retazos de un colectivo. San Luis: Nueva Editorial Universitaria.

Pérez Gómez, A. (1996). Autonomía profesional del docente y control democrático. En VV. AA. Volver a pensar la educación. Madrid: Morata.

Pievi, N., y Bravin, C. (2009). Documento metodológico orientador para la investigación educativa. (1 ${ }^{\mathrm{a}} \mathrm{ed}$ e). Buenos Aires: Ministerio de Educación de la Nación. Recuperado de http://cedoc.infd.edu.ar/upload/Documento_metodologico_investigacion.pdf

Pine, G. (1981). Collaborative action research. The integration of research and service. En Annual Meeting of American Association of Colleges for Teacher Education. Detroit. 
Rama, C. (2006). La tercera reforma de la educación superior en América Latina. Buenos Aires: Fondo de Cultura Económica.

Rockwell, E. (2000). Tres planos para el estudio de las culturas escolares: El desarrollo humano desde una perspectiva histórico-cultural. Interações, (5) [en línea]. Recuperado de: http://148.215.2.11/articulo. oa?id=35450902

Romano, P. (2011). Sujeto de la formación docente, sujeto a la formación docente. Repensando la normatividad del deber ser. En J. A. Yuni (Ed.). La formación docente. Complejidades y ausencias. Facultad de Humanidades. Universidad Nacional de Catamarca: Encuentro Grupo Editor.

Soria, M. G, Anquín, A, Bellavilla, E. (2011). Investigación y formación docente sobre prácticas educativas situadas y contextuadas. En J. A. Yuni (Ed.). La formación docente. Complejidades y ausencias. Facultad de Humanidades. Universidad Nacional de Catamarca: Encuentro Grupo Editor.

Sánchez Gamboa, S. (2010). Saberes escolares y conocimiento: conflicto de las pedagogías de la respuesta y las pedagogías de la pregunta. Revista Praxis y Saber, 1(1), 77-101.

Sarlé, P. M. (2007). Cuando de investigar se trata... La investigación como espacio en los IFD. Revista e- Eccleston. Formación Docente, 3(7). Recuperado de http:// ieseccleston.caba.infd.edu.ar/sitio/index.cgi?wid_ seccion $=25$
Schön, D. (1992). La formación de profesionales reflexivos. Barcelona: Paidós.

Stenhouse, L. (1991). Investigación y desarrollo del currículum. Madrid: Morata.

Southwell, M. (2011). Docencia, tradiciones y nuevos desafíos en el escenario contemporáneo. En J. A. Yuni (Ed.). La formación docente. Complejidades y ausencias. Facultad de Humanidades. Universidad Nacional de Catamarca: Encuentro Grupo Editor.

Vaillant, D. (2007). La identidad docente. Ponencia presentada en el I Congreso Internacional, Nuevas Tendencias en la Formación Permanente del Profesorado. Barcelona, 5, 6 y 7 de septiembre de 2007. GTDPREAL-ORT. Recuperado de: www.ub.edu/obipd/ docs/la_identidad_docente_vaillant_d.pdf

Vassiliades, A. (2012). Regulaciones del trabajo de enseñar en la provincia de Buenos Aires: posiciones docentes frente a la desigualdad social y educativa. (Tesis Doctorado). Facultad de Filosofía y Letras, Universidad de Buenos Aires, Buenos Aires. Recuperado de http://catalogosuba.sisbi.uba.ar/tesis/index.php/ record/view/651248

Ward, B., Tikunoff, W. (1982). Collaborative research. Washington: National Institute of Education. Teaching and Learning Program. 